[RADIOCARBON, Vol. 37, No. 1, 1995, P. 7-10]

\title{
MAMMOTH EXTINCTION: TWO CONTINENTS AND WRANGEL ISLAND
}

\author{
PAUL S. MARTIN
}

Desert Laboratory, The University of Arizona, Tucson, Arizona 85721 USA

and

\section{ANTHONY J. STUART}

\section{Norfolk Museums, Norwich NR1 3JU England}

A harvest of 300 radiocarbon dates on extinct elephants (Proboscidea) from the northern parts of the New and Old Worlds has revealed a striking difference. While catastrophic in North America, elephant extinction was gradual in Eurasia (Stuart 1991), where straight-tusked elephants (Palaeoloxodon antiquus) vanished 50 millennia or more before woolly mammoths (Mammuthus primigenius). The range of the woolly mammoths started shrinking before $20 \mathrm{ka}$ ago (Vartanyan et al. 1995). By $12 \mathrm{ka} \mathrm{BP}$, the beasts were very scarce or absent in western Europe. Until the dating of Wrangel Island tusks and teeth (Vartanyan, Garrutt and Sher 1993), mammoths appeared to make their last stand on the Arctic coast of Siberia ca. $10 \mathrm{ka}$ BP. The Wrangel Island find of dwarf mammoths by Sergy Vartanyan, V. E. Garrut and Andrei Sher (1993) stretched the extinction chronology of mammoths another $6 \mathrm{ka}$, into the time of the pharaohs.

Not since the early years of ${ }^{14} \mathrm{C}$ dating, when laboratory protocols for sample selection and pretreatment were not standardized or well understood by consumers of dates (see, e.g., Martin 1958 and Hester 1960), has anyone seriously advanced the thought that mammoths or mastodons survived into the mid-Holocene. Those North American Holocene dates of yore were not replicated and could not be supported stratigraphically and geochemically. They moulder in the graveyard of unverified measurements. The 20 new dates on teeth and tusk from Wrangel Island range from 6148 to 2192 BC (Vartanyan et al. 1995). They are accompanied by standardized test measurements of the St. Petersburg Laboratory as well as independent replications (Long, Sher and Vartanyan 1994). Frozen ground at the latitude of Wrangel $\left(70.5^{\circ} \mathrm{N}\right)$ is a very favorable environment for preservation of skeletal collagen, thus ideal for dating. The new data set appears unassailable. What does it mean?

For one thing, it appears discordant with the idea that a Younger Dryas (YD) cold snap or climatic upset roughly 11-10 ka BP forced megafaunal extinction (Berger 1991). While the YD falls hard on the heels of extinction of North American mammoths (Mammuthus columbi), horses, camels, ground sloths, extinct mountain goats, sabertooths and others, as well as Old World giant deer (Megaloceros giganteus) in Ireland, all other Old World extinctions precede or postdate the YD (Fig.1; Stuart 1991).

Ironically, the YD climatic signal is strongest in Western Europe. Even before ${ }^{14} \mathrm{C}$ dating, it was the basis for correlating pollen diagrams. On oceanic islands around the globe, most doomed genera of birds, mammals and reptiles would disappear, like the Wrangel dwarf mammoths, long afterward, in the Holocene (Steadman 1995).

Admittedly, the fossil record on many of the oceanic islands has yet to be traced into YD or earlier time. Late Glacial or earlier extinction pulses remain a possibility. However, when faunas of such an age are known, there is no extinction pulse at any time within the ${ }^{14} \mathrm{C}$ range, prior to the late Holocene (Steadman 1995). Neither the YD, nor the warm-cold oscillations in Greenland core ices known as Dansgaard-Oeschger events that coincide with ice transport of lithic material into the North Atlantic (Bond and Lotti 1995), nor any other independently established climatic perturbation 

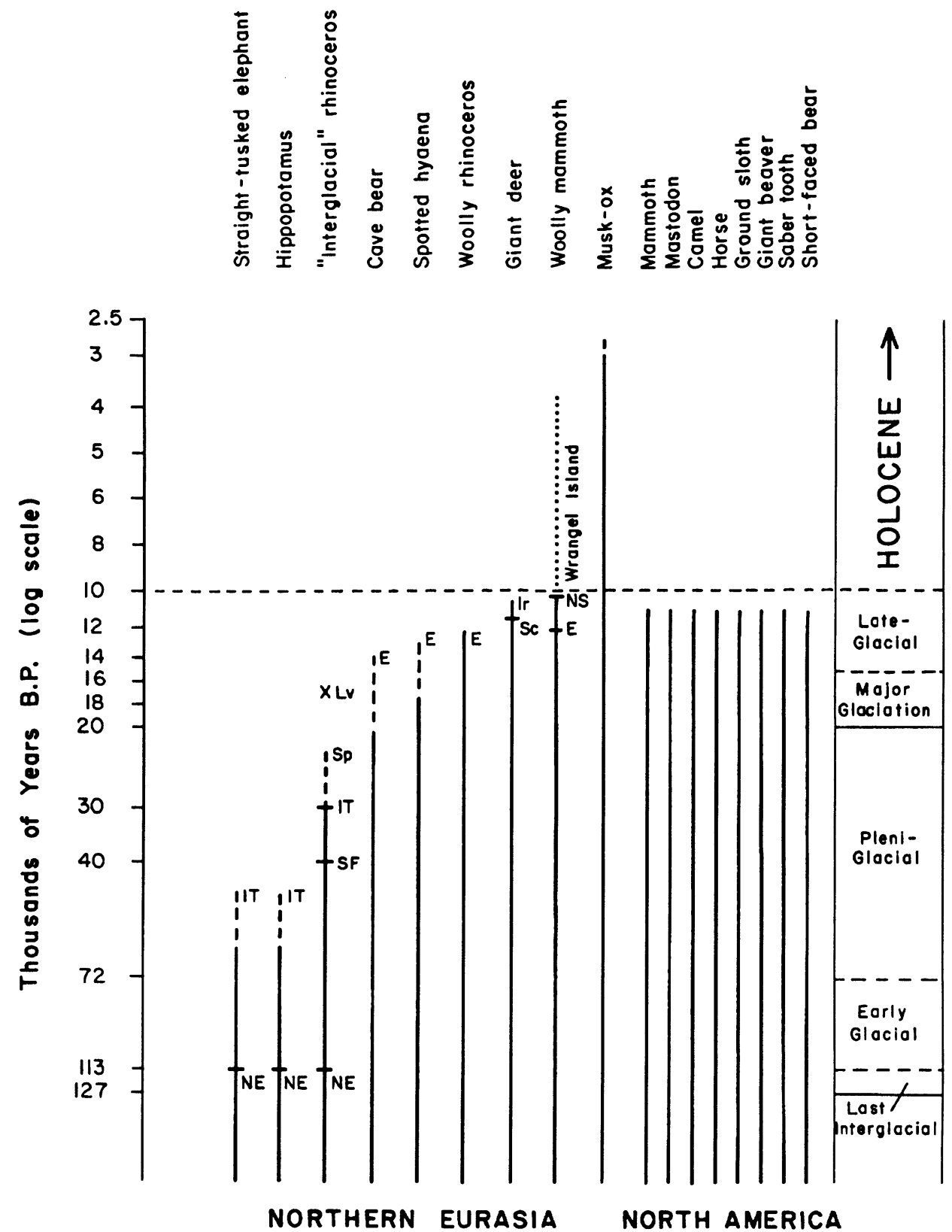

Fig. 1. Large mammals that vanished from northern Eurasia are compared with some of those that vanished from North America. Loss of the former was sequential over $\sim 50 \mathrm{ka}$; the latter loss was catastrophic at $11 \mathrm{ka} \mathrm{BP}$. NE = northern and central Europe; IT = Italy; SF = southern France; Sp = Spain; Lv = Levant; $\mathrm{E}=$ England; $\mathrm{Sc}=\mathrm{Scan}$ dinavia; Ir = Ireland; NS = north-central Siberia. Straight-tusked elephant = Palaeoloxodon antiquus; hippopotamus = Hippopotamus amphibius; "interglacial" rhinoceros = Dicerorhinus spp.; cave bear = Ursus spelaeus; spotted hyaena = Crocuta crocuta ; wooly rhinoceros = Coelodonta antiquitatis; giant deer = Megaloceros giganteus; wooly mammoth = Mammuthus primigenius; musk-ox = Ovibus moschatus. North American extinctions: mammoth = Mammuthus spp.; mastodon = Mammut americanum; camel = Camelops hesternus; horse = Equus spp.; ground sloth = Nothrotheriops shastensis; saber-tooth = Smilodon fatalis; and short-faced bear = Arctodus simus . 
dated by ${ }^{14} \mathrm{C}$ coincides with the extinction pattern outlined above (Fig.1). Although further tests are needed, the extinctions that do not coincide with the YD are as noteworthy as cases that do (or might) fall within its time range.

In western North America, the source of the best ${ }^{14} \mathrm{C}$ dates on megafaunal extinctions in the New World (Stuart 1990), the event coincides with Clovis (Llano culture) origins (Haynes 1991, 1993). The number of sites in which mammoth bones were found with artifacts is small, and no bones of horse, camel and ground sloths (to cite a few examples) have been found in undeniable association with stone or bone tools. If the Paleolithic invaders of the New World forced the extinctions, as some propose, it was remarkably rapid, a "blitzkrieg" (Mosimann and Martin 1975), or a "mammoth undertaking" (Diamond 1992). Obviously, the catastrophic model will not work if all New World generic extinctions were not synchronous. Some believe that they were not (Grayson 1991). Critics, in turn, bear the burden of demonstrating how a climatic pulse could force the disparate extinction sequence between the New and the Old Worlds (Fig.1).

Another climatic model for mammoth extinction deserves mention. Beringian paleontologists, Russian, Canadian and Alaskan, have long viewed the coming of the Holocene in the far north, with its string bogs, sphagnum, ericads and other herbivore-resistant plants, and with deep snows in winter, as uninhabitable for mammoths and the extinct steppe fauna of Glacial times (Guthrie 1990 and references therein). In the case of Wrangel Island, even before the discovery of Holocene dwarf mammoths, Russian botanists had reported an unusually rich and palatable assemblage of steppe tundra plants, including 15 species of grasses, 4 of wormwood (Artemisia), 10 legumes, many Rosaceae and very few Ericaceae (Yurtsev 1982). Wrangel sounds like an ideal place to survive the loss of the mammoth steppe.

Nevertheless, Guthrie's argument leaves unanswered questions of the suitability of other relict patches of grasses and palatable steppe plants elsewhere in Eurasia and North America. Were there no other Wrangel-size refugia for woolly mammoths? What of vast expanses of steppe with dozens of genera of grasses, legumes and Rosaceae and many species of Artemisia and palatable Chenopodiceae in the high dry plateaus and valleys of eastern Eurasia and western North America? Would not western North America offer suitable continental climates for various species of mammoth? Special-case environmental arguments that serve to explain regional extinctions, such as the Beringian mammoth steppe, may sound plausible, until one attempts to generalize more widely.

On one matter all "extinctionists" interested in the fate of mammoths can agree: ${ }^{14} \mathrm{C}$ dating has done more to clarify events than any other analysis. The method offers a unique opportunity to evaluate extinctions in many corners of the earth over the last $50 \mathrm{ka}$. Bones of the youngest extinct large mammals (including mammoths) in the frozen ground of Arctic and subarctic latitudes may prove to be of any age. It takes a serious effort to wade through dozens of dates, most of which are too old by many thousands of years to approach the last millennium when extinction likely occurred. Russian paleontologists and Russian ${ }^{14} \mathrm{C}$ laboratories have worked hard on this problem. They are to be congratulated. Their work confirms dramatically an extinction chronology of mammoths in the Old World that was much more gradual than the one in the New World (Fig. 1). In the New World and increasingly in the Old, the chronology is in step with the spread of prehistoric humans.

\section{REFERENCES}

Berger, W. H. 1991 On the extinction of the mammoth: Science and myth. In Muller, D. W., McKenzie, J. A. and Weissert, H., eds., Controversies in Modern Geology. London, Academic Press: 115-132.
Bond, G. C. and Lott, R. 1995 Iceberg discharges into the north Atlantic on millennial time scales during the last glaciation. Science 267: 1005-1010.

Diamond, J. 1992 The Third Chimpanzee: The Evolution 
and Future of the Human Animal. New York, HarperCollins: $407 \mathrm{p}$.

Guthrie, R. D. 1990 Frozen Fauna of the Mammoth Steppe: The Story of Blue Babe. Chicago, The University of Chicago Press: 323 p.

Grayson, D. K. 1991 Late Pleistocene mammalian extinctions in North America: Taxonomy, chronology, and explanations. Journal of World Prehistory 5: 193-231.

Haynes, C. V., Jr. 1991 Geoarcheological and paleohydrological evidence for a Clovis-age drought in North America and its bearing on extinction. Quaternary Research 35: 438-450.

1993 Contributions of radiocarbon dating to the geochronology of the peopling of the New World. In Taylor, R. E., Long, A. and Kra, R. S., eds., Radiocarbon After Four Decades: An Interdisciplinary Perspective. New York, Springer-Verlag: 355-374.

Hester, J. J. 1960 Late Pleistocene extinctions and radiocarbon dating. American Antiquity 26: 58-77.

Long, A., Sher, A. and Vartanyan, S. 1994. Holocene mammoth dates. Nature 369: 364

Martin, P. S. 1958 Pleistocene ecology and biogeography of North America. In Hubbs, C. L., ed., Zoogeography. Washington, D.C., American Association for the Advancement of Science Publication 51: 375-420

Mosimann, J. E. and Martin, P. S. 1975 Simulating overkill by paleoindians. American Scientist 63: 304-313.

Steadman, D. W. 1995 Prehistoric extinctions of Pacific Island birds: Biodiversity meets zooarchaeology. Science 267: 1123-1131.

Stuart, A. J. 1991 Mammalian extinctions in the late Pleistocene of northern Eurasia and North America. Biological Reviews 66: 453-562.

Vartanyan, S. L., Arslanov, Kh. A., Tertychnaya, T. V., Chernov, S. 1995 Radiocarbon Dating Evidence for Mammoths on Wrangel Island, Arctic Ocean, until 2000 BC. Radiocarbon, this issue.

Vartanyan, S. L., Garrutt,V. E., Sher, A. V. 1993 Holocene dwarf mammoths from Wrangel Island in the Siberian Arctic. Nature 382: 337-340.

Yurtseev, B. A. 1982 Relicts of the xerophyte vegetation of Beringia. In Hopkins, D. M., Mathers, J. W., Jr., Schweger, C. E. and Young, S. B., eds. Paleoecology of Beringia. New York, Academic Press: 157-178. 